\title{
Direct Ink Writing of Gypsum: Developing a Printable Gypsum Paste
}

\author{
ZHOU Hongli ${ }^{1}$, CAI Zhiyong ${ }^{1}$, WANG Xiaofeng ${ }^{1}$, ZENG Jin ${ }^{2}$, FENG Yan ${ }^{1}$, PENG Chaoqun ${ }^{1}$, WANG Richu ${ }^{1}$ \\ (1. School of Materials Science and Engineering, Central South University, Changsha 410083, China; 2. School of Metallurgy \\ and Environment, Central South University, Changsha 410083, China)
}

\begin{abstract}
Gypsum is a common material for statues, building, and casting molds (alloys and ceramics). Due to the incomplete hydration reaction between water and gypsum, it is difficult to print high-strength gypsum products using $3 \mathrm{D}$ printing techniques such as Binder Jetting. To enhance its strength, the hydration reaction should be completely performed, which could be fulfilled by direct ink writing (DIW). However, the reaction in the gypsum paste for DIW is so fast that less time is left for operating a 3D printer. In this work, a printable gypsum paste with a reasonable setting time was developed to print 3D gypsum structures via direct ink writing. A retarder and a thickener were introduced into the paste to prolong its setting time for operating and tailor its rheological property for printing, respectively. The setting time, expansion and rheological properties of the pastes were tested by the Vicat apparatus, consistometer and rheometer, respectively. The results show that citric acid (CA) is a suitable retarder, although decreases its compressive strength due to the directional grown gypsum crystals resulting from the selective adsorption of CA on gypsum powder, while hydroxypropyl methylcellulose (HPMC) is an acceptable thickener, which affects forming flocculation structure in the paste, resulting in higher viscosity and shear modulus. Optimal amounts of CA and HPMC for the printable gypsum paste are $0.6 \%$ and $0.3 \%$ (in mass), respectively. Three-dimensional gypsum structures such as spider web and scaffold are successfully printed via direct ink writing, which compressive strength is around $20 \mathrm{MPa}$, much higher than that printed via Binder Jetting.
\end{abstract}

Key words: direct ink writing; gypsum; retarder; thickener; rheological property; casting

Gypsum is a common gel material, because of its green environmental protection, low production cost, and has become one of the most competitive building materials such as a building interior decoration ${ }^{[1]}$, and an advanced industrial material ${ }^{[2]}$, etc. Especially, gypsum is used as a mold material for metal casting due to its good surface quality, low cost, and less energy consumption ${ }^{[3]}$. The most widely utilized traditional gypsum casting process is Investment Casting, also named Lost Wax Casting. Firstly, a designed and fabricated wax mold is covered by a gypsum paste which is hardened via hydration reaction; then the max mold is removed by heating. Molten metal is cast into the gypsum mold to form parts $^{[4]}$. Obviously, this manufacturing process is so complex, waste-time, high-cost and even unacceptable for parts with complex-shape ${ }^{[5-7]}$.

The upcoming $3 \mathrm{D}$ printing technology, which is a landmark technology of major changes in the modern manufacturing industry, has provided a powerful route to improve this method. 3D printing technology is prone to realize complex samples with special external and internal forms ${ }^{[8]}$, possessing the characteristics of controllable accuracy, time-saving, and cost-saving ${ }^{[9-11]}$. Thus, to print three-dimensional gypsum mold, the Massachusetts Institute of Technology (MIT) developed a 3D printing technology named Powder Bed Binder Jet (PBBJ, also named as $3 \mathrm{D}$ printing, 3DP) in $1992^{[12]}$. This method is based on binding powder particles or pellets, either by injecting a reaction solution or by a polymeric binder in a route of layer-by-layer until the structure is completed ${ }^{[13-15]}$. Three-dimensional gypsum parts via $\mathrm{PBBJ} / 3 \mathrm{DP}$ have been widely applied in areas such as Civil Engineering, Rock Mechanics, Medicine and Casting, etc ${ }^{[16-20]}$. However, the compressive strength and Young's modulus of these

Received date: 2021-10-02; Revised date: 2021-12-02; Published online: 2021-12-24

Foundation item: Natural Science Foundation of Hunan Province (2020JJ4729)

Biography: ZHOU Hongli (1996-), female, Master candidate. E-mail: summertimezhl@163.com 周红莉(1996-), 女, 硕士研究生. E-mail: summertimezhl@163.com

Corresponding author: WANG Xiaofeng, associate professor. E-mail: wangxiaofeng@csu.edu.cn 王小锋, 副教授. E-mail: wangxiaofeng@csu.edu.cn 
parts are not high, only $8.63 \mathrm{MPa}$ and $1.74 \mathrm{GPa}$, respectively ${ }^{[21]}$. The reason is that gypsum hydration happened in the mixture of particles/ pellets and the solution/binder is not complete. It is attributed to less water and the short reaction time during the printing, which is an intrinsic drawback of PBBJ/3DP. Although some treatment processing such as dipping process $^{[21]}$, heat-treatment ${ }^{[22]}$ and pre-moisturize ${ }^{[23]}$ have been developed to improve its mechanic properties, it doesn't work effectively, only make compressive strength reach $11 \mathrm{MPa}$. Thus, more wide application of 3D gypsum parts is blocked by their mechanical properties.

Direct ink writing (DIW) is one of the most promising and inexpensive $3 \mathrm{D}$ printing techniques ${ }^{[24]}$. It depends on continuous ink/paste to assemble a three-dimensional structure in a layer-by-layer build sequence ${ }^{[25]}$. The paste with special rheological property is pressed out from a nozzle smoothly, and the printed figures maintain their shape upon being released without pressure. Because of its material flexibility and low cost, DIW is used extensively in many fields, such as ceramics, metals and polymers. For printing gypsum, DIW provides adequate hydration, which is a promise to high strength mold, similar to the traditional molding process ${ }^{[26]}$. Compared with printing gypsum Binder Jetting ${ }^{[16-20]}$, it avoids the generation of pores and guarantees to obtaining parts with higher mechanical strength. However, the reaction of gypsum hydration is so fast that less time for operating DIW, that is, the transition time from flow- to solid-status is too short. Besides, low shear elastic modulus and high flowability of gypsum paste, which are resulted from bleeding of gypsum, are unfriendly to DIW.

In this work, in order to prolong hydration for operating and tailor the rheological property of gypsum for printing, retarders and thickeners were introduced into its paste. The optimal retarder and thickener were selected, according to the setting time, expansion degree, rheological property of gypsum paste. Moreover, hydration of the gypsum paste with a retarder and a thickener was analyzed. A printable gypsum paste for DIW has been developed and printed into three-dimensional parts such as spider webs and scaffolds.

\section{Experimental}

\subsection{Raw materials}

The gypsum powders are commercial $\alpha$-hemihydrate gypsum (Zaozhuang Jinzheng Gypsum Co., Ltd). The $\alpha$-calcium sulfate hemihydrate content is about $98 \%$ (in mass). The water consumption for standard consistency is 0.41 , and the specific surface area of gypsum is $4122 \mathrm{~cm}^{2} / \mathrm{g}$, the average particle size of gypsum powder is $75 \mu \mathrm{m}$.

Three retarders were used: Tartaric acid (TA, Xilong Scientific Co., Ltd), sodium tripolyphosphate (STPP, Xilong Scientific Co., Ltd), citric acid (CA, Xilong Scientific Co., Ltd). Two thickeners were used: Hydroxypropyl methylcellulose (HPMC, Shanghai Aladdin Biochemical Technology Co., Ltd, viscosity (2.0\% (in mass), $10000 \mathrm{mPa} \cdot \mathrm{s}$ ), methylcellulose (MC, Shanghai Aladdin Biochemical Technology Co., Ltd). All additives were AR grade.

\subsection{Setting time and fluidity test}

Firstly, a retarder (tartaric acid, sodium triphosphate or citric acid dosage set at $0.2 \%, 0.4 \%, 0.6 \%, 0.8 \%$ and $1.0 \%$ (in mass) of gypsum powder) and a thickener (HPMC or MC dosage set at $0.1 \%, 0.2 \%, 0.3 \%, 0.4 \%$, $0.5 \%$ (in mass) of gypsum powder) were mixed with water and dissolved respectively. And then gypsum powders were added to the solution to form pastes. The pastes were manually stirred for about $120 \mathrm{~s}$, and then the planetary agitator was used to mix each of them clockwise and counterclockwise for $15 \mathrm{~s}$. The setting time of gypsum paste was determined according to GB/T9776-2008 (China National Standard for Building Gypsum). Setting time measured by a Vicat apparatus. The initial setting time is the time when the needle cannot reach the bottom of the steel ring at a height of $40 \mathrm{~mm}$, and the final setting time is the time when the needle cannot penetrate the paste. The expansion degree of gypsum paste was determined according to GB9776- 88 (China National Standard for Building Gypsum), the gypsum paste was pulled out from the pipe with an inner diameter of $50 \mathrm{~mm}$ and height of $100 \mathrm{~mm}$ to evaluate the expansion degree of gypsum paste (fluidity). The expansion degree is the average of the two vertical cross diameters. Each data was averaged over three experimental values.

\subsection{Paste preparation and rheology measure- ments}

Firstly, different amounts of retarders and thickeners were evenly mixed in some water to form a solution, and then the weighed gypsum powder was poured into the solution and stirred manually for $2 \mathrm{~min}$. Then, it was put into a planetary agitator and mixed for $15 \mathrm{~s}$ clockwise and counterclockwise, respectively. The rheological behavior of the plaster was studied by using a rheometer (AR2000EX, TA) with a parallel plate $(\phi 40 \mathrm{~mm})$. Measurements using the shear stress scanning mode oscillation technique showed a steady increase in shear stress from $1 \mathrm{~Pa}$ to $1000 \mathrm{~Pa}$ at a fixed frequency of $1 \mathrm{~Hz}$. All rheological measurements were performed at $25{ }^{\circ} \mathrm{C}$. 


\subsection{Direct ink writing}

The 3D structures were printed by a pressurecontrolled 3D printer (System 30M, Hyrel International, Norcross, GA, USA). The paste was poured into a $10 \mathrm{~mL}$ syringe which was put into a planetary agitator to deform bubbles. The printer position adjustment system is mounted on a moving $X-Y-Z$ class controlled by a computer regulator to ensure that the paste is accurately deposited on a glass plate. The $3 \mathrm{D}$ design is carried out by Auto CAD, and slice setting is provided by Prusa Slicer software to determine the layer height, printing speed, and extrusion width, etc. The extrusion speed multiplier of the printer is set as 1.5 and the nozzle diameter is $0.84 \mathrm{~mm}$. The printed gypsum sample is placed at room temperature $\left(25{ }^{\circ} \mathrm{C}\right)$ for $4-6 \mathrm{~h}$ for hardening and then placed in a $60{ }^{\circ} \mathrm{C}$-thermostat drying oven for strength curing.

\section{$1.5 \mathrm{X}$-ray analysis}

The early hydration products of gypsum paste were studied using X-ray powder diffraction (XRD, D/max2500, Japan). At each specified hydration time, the hydration reaction was immediately terminated by immersing into an ethanol solution. The immature gypsum was ground into a powder, then separated by vacuum filtration and dried in a vacuum oven at $40{ }^{\circ} \mathrm{C}$. These tests were carried out at $40 \mathrm{kV}, 30 \mathrm{~mA}, 4\left(^{\circ}\right) / \mathrm{min}, 5^{\circ}$ to $80^{\circ}$ with a step size of $0.02^{\circ}$.

\subsection{SEM test}

Scanning electron microscope (SEM, Quanta, USA) was used to analyze the microstructure of gypsum samples. At each specified hydration time, the gypsum paste was immediately terminated in an excess ethanol solution and the gypsum was ground into a powder, adhered to a sample holder with a conductive adhesive, and then the sample holder was placed on an ion sputtering apparatus covered with conductive film ( $\mathrm{Au}$ ). After the vacuum is less than $5 \times 10^{-5} \mathrm{~Pa}$, set the electron gun acceleration voltage at $15 \mathrm{kV}$, probe current at $50 \mu \mathrm{A}$, working distance at $8-10 \mathrm{~mm}$, and then open the beam to observe the image.

\subsection{Mechanical properties}

The compressive strength of the samples was tested using a universal testing machine (MTS) with a loading speed of $0.3 \mathrm{kN} / \mathrm{s}$ and a measurement range of $3 \mathrm{~d}$ cured samples. The compressive strength was tested following the national standard GB/T 9776-2008 (China National Standard for Building Gypsum). The samples were grouted and printed gypsum parts. The grouted samples include one sample without additives, one sample with $0.6 \%$ (in mass) CA, one sample with $0.6 \% \mathrm{CA}$ and $0.3 \%$ HPMC (in mass). The samples' shape was a cylinder with a diameter of $50 \mathrm{~mm}$ and a height of $100 \mathrm{~mm}$. The cubic gypsum samples were printed with dimensions of
$40 \mathrm{~mm} \times 40 \mathrm{~mm} \times 10 \mathrm{~mm}$ and the cylindrical gypsum samples were printed with dimensions of $30 \mathrm{~mm}$ in diameter and $10 \mathrm{~mm}$ in height. Each data was averaged over three experimental values.

\section{Results}

\subsection{Effect of retarder on gypsum paste}

To prolong the setting time of gypsum for printing, a retarder should be added to the paste to retard its hydration. Three retarders, tartaric acid, sodium tripolyphosphate, and citric acid, were selected as candidates. The effect of retarder on setting time is shown in Fig. 1(a). It can be seen that the setting time of the paste increases with increasing admixture and the effect of $\mathrm{CA}$ is the most significant. As the content of CA is $0.4 \%$ (in mass), the initial setting time of gypsum paste is $199 \mathrm{~min}$, which is suitable to direct ink writing. However, the content of sodium tripolyphosphate and tartaric acid is $0.6 \%$ (in mass), the time is only $\sim 50 \mathrm{~min}$. It is much shorter than that time of CA, which is consistent with others' work ${ }^{[27]}$. The setting time restricts the printing operation. The longer the setting time is, the more the operation time for printing is. Based on this rule, $\mathrm{CA}$ is chosen as the suitable one.

Fig. 1(b) shows that fluidity varies with CA at different hydration time. The degree of expansion is an evaluation of loss fluidity. The addition of CA plays a role on the degree of expansion ${ }^{[28]}$, which is not affected by the amount of CA. Besides, the fluidity of paste with CA could be maintained and even is not significantly changed with time. For example, the initial fluidity of paste with $0.1 \%$ (in mass) CA is $\sim 200 \mathrm{~mm}$ and reduced to $\sim 150 \mathrm{~mm}$ after $60 \mathrm{~min}$. However, the fluidity of paste without CA is changed from $180 \mathrm{~mm}$ to $0 \mathrm{~mm}$ in $20 \mathrm{~min}$. This confirms that $\mathrm{CA}$ is an effective retarder to prolong the time for operating direct ink writing.

A rheology test was performed on the gypsum paste to further study its viscoelastic behavior, as shown in Fig. 1(c). The pastes exhibit typical shear-thinning behavior. There is obviously yield stress as illustrated in each curve, which is the point at which the paste transitions from elastic reversible deformation to irreversible flow ${ }^{[29]}$. That is, below the value of yield stress, the paste is purely elastic rheology ${ }^{[30]}$. Moreover, Fig. 1(c) also indicates that the amount of citric acid plays an important role in this value. According to the data in Fig. 1(c), the yield stresses of pastes with different amounts of critic acid are shown in Fig. 1(d). The yield stress of paste increases with CA content, reaches the maximum as the content is $0.6 \%$ (in mass), and then decreases with increasing CA content. The maximum value of yield stress is around $25 \mathrm{~Pa}$, 

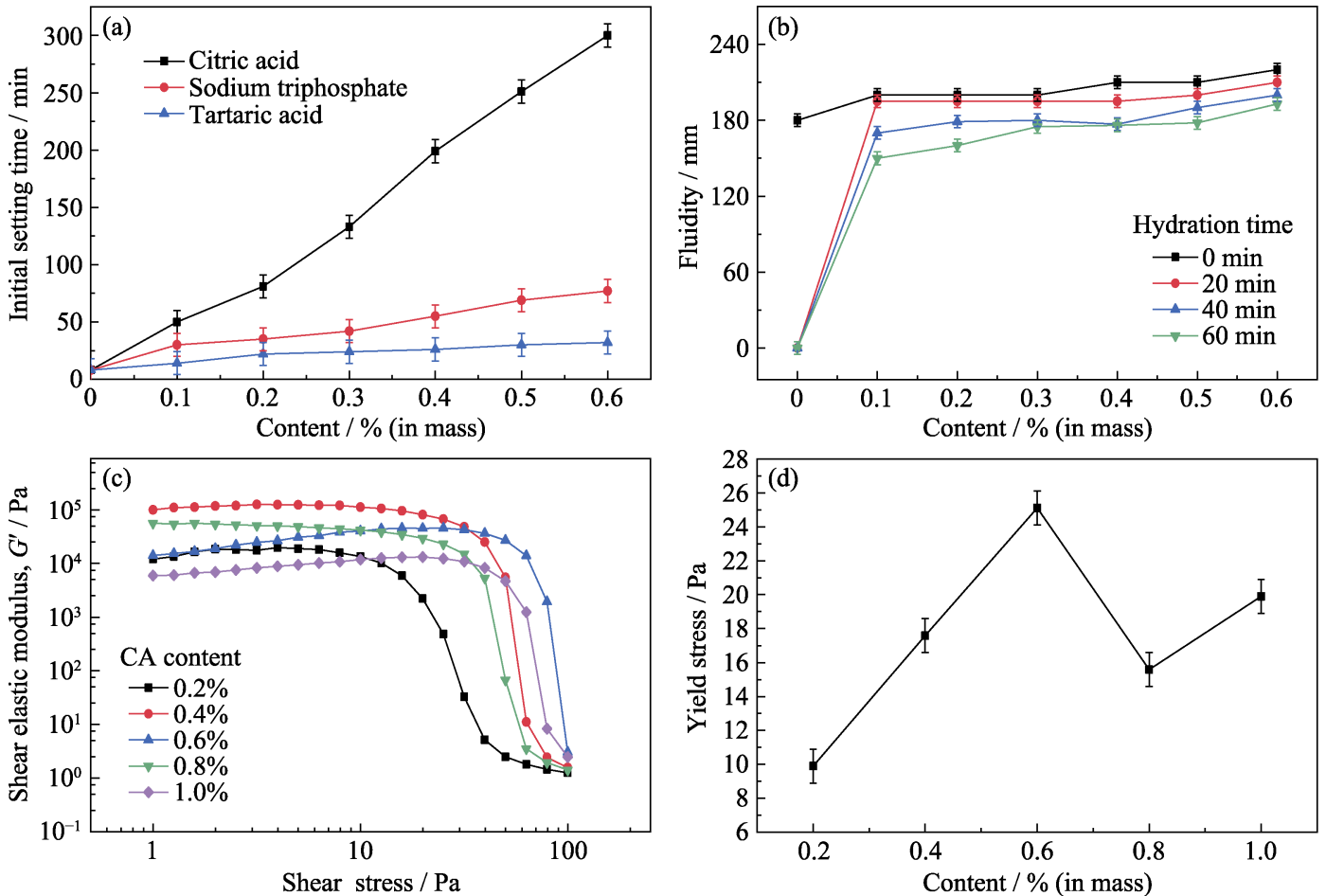

Fig. 1 Effect of retarders on gypsum paste

(a) Setting time $v s$ content of retarder; (b) Fluidity $v s$ content of citric acid (CA) in the gypsum paste; (c) Shear elastic modulus $v s$ shear stress; (d) Yield stress $v s$ content of CA

which nears the gravity per unit volume, $27 \mathrm{~Pa}$ (calculated from the density of gypsum paste, $2.7 \mathrm{~g} / \mathrm{cm}^{3}$ ). This shows that the paste could support itself gravity. Last but not least, the shear elastic modulus of paste with $0.6 \%$ (in mass) CA is relatively high (Fig. 1(c)), $\sim 27 \mathrm{kPa}$, which indicates that the paste has high rigidity to keep its shape. Therefore, the optimal amount of $\mathrm{CA}$ in the gypsum paste is $0.6 \%$ (in mass).

\subsection{Effect of thickener on gypsum paste}

To further improve the rheological property for DIW, HPMC and MC are introduced into gypsum paste as thickeners. Their influence on the initial setting time of gypsum paste is shown in Fig. 2(a). The initial setting time of gypsum paste containing HPMC or MC is prolonged. Especially, as the HPMC content reaches $0.4 \%$ (in mass), the initial setting time is the longest, $\sim 14 \mathrm{~min}$. As a result, the addition of HPMC or MC in the paste is helpful to prolong the setting time.

The effect of thickeners on paste fluidity is shown in Fig. 2(b). The fluidity of gypsum pastes decreases with the content of HPMC or MC increasing, and the effect of HPMC is better. The expansion degree of paste without thickener is $180 \mathrm{~mm}$, and that with $0.3 \%$ (in mass) HPMC reduces to $80 \mathrm{~mm}$. However, the expansion degree of paste with $0.3 \%$ (in mass) MC is still $175 \mathrm{~mm}$. And thus, to improve the fluidity of paste, HPMC prefers to $\mathrm{MC}$.
To set the content of HPMC, a rheology test was also performed on the gypsum paste with $0.6 \mathrm{wt} \%$ (in mass) CA and different amounts of HPMC, as shown in Fig. 2(c). All of the pastes exhibit shear-thinning behavior. The shear elastic modulus and yield stress increase with HPMC content. It is attributed to HPMC wraps water molecules easily and quickly, accelerating the formation of the gypsum flocculation structure ${ }^{[31]}$. For a printable paste, high shear elastic modulus and suitable yield stress are required. The yield stress should be the minimum value but above the gravity. The yield stress and elastic shear modulus of the paste with $0.6 \%$ (in mass) CA and $0.3 \%$ (in mass) HPMC are $\sim 50 \mathrm{~Pa}$ and $\sim 0.9 \mathrm{MPa}$, respectively, which are large enough to keep the paste from collapsing.

\subsection{Structure and mechanical properties of three-dimensional gypsum}

The printable gypsum paste with CA and HPMC was printed into 3D structures of scaffold and spider by DIW, as shown in Fig. 3(a-f). It is clear that the 3D complex structures retained their integrity after printing and drying, and the surfaces are flat. Note that the shape of the printed line and opening holes in the $Z$-axis was slightly changed. The reason is that the deposited filaments have to through a bridge path that requires high elastic modulus and yield stress to avoid collapse and maintain their print shape. Figs. 3(g-i) demonstrate the microstructure of printed gypsum parts. The layers 

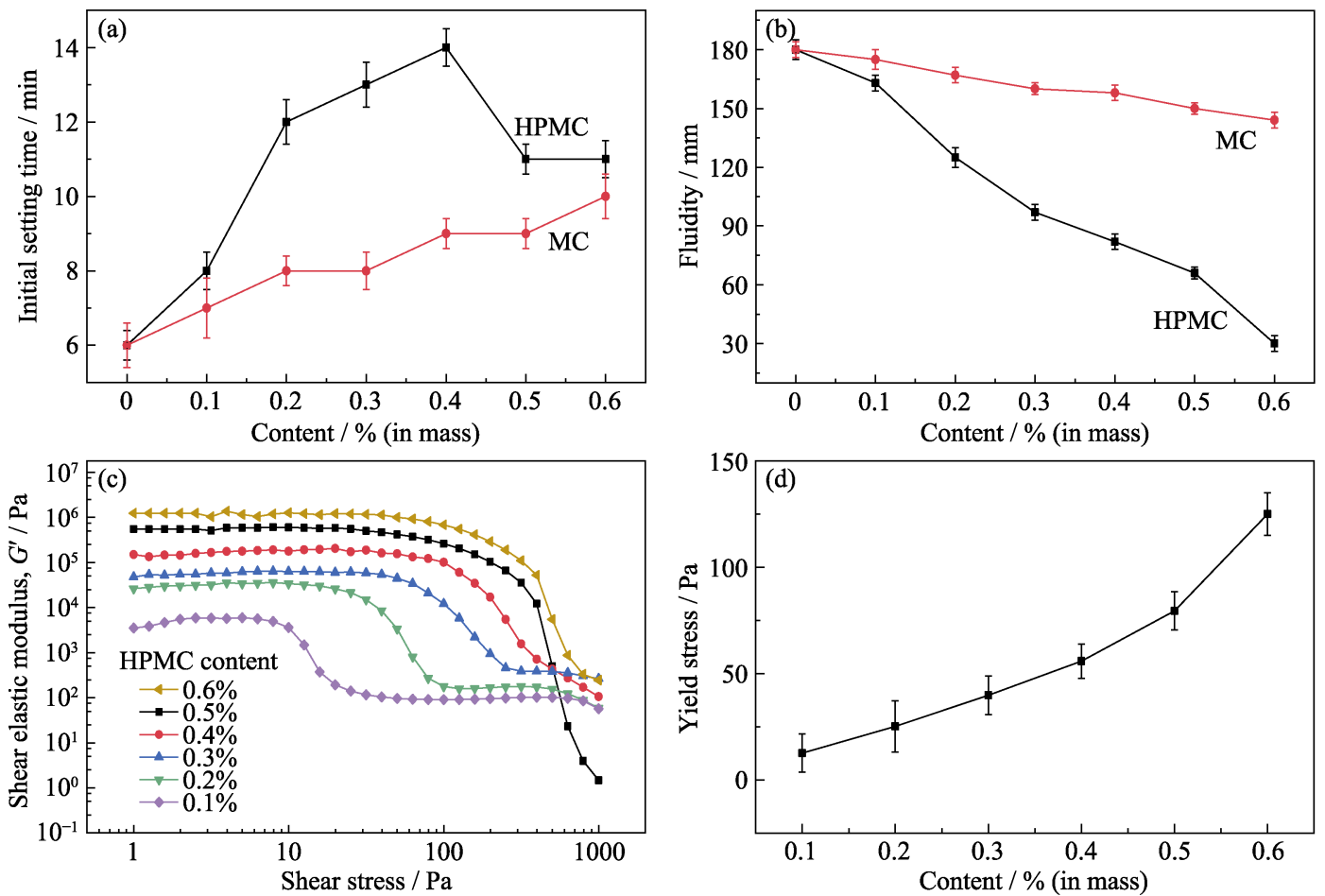

Fig. 2 Effect of thickener on gypsum paste

(a) Setting time $v s$ content of thickeners; (b) Fluidity $v s$ content of thickener; (c) Shear modulus of elasticity of HPMC with different dosage; (d) Yield stress vs content of HPMC
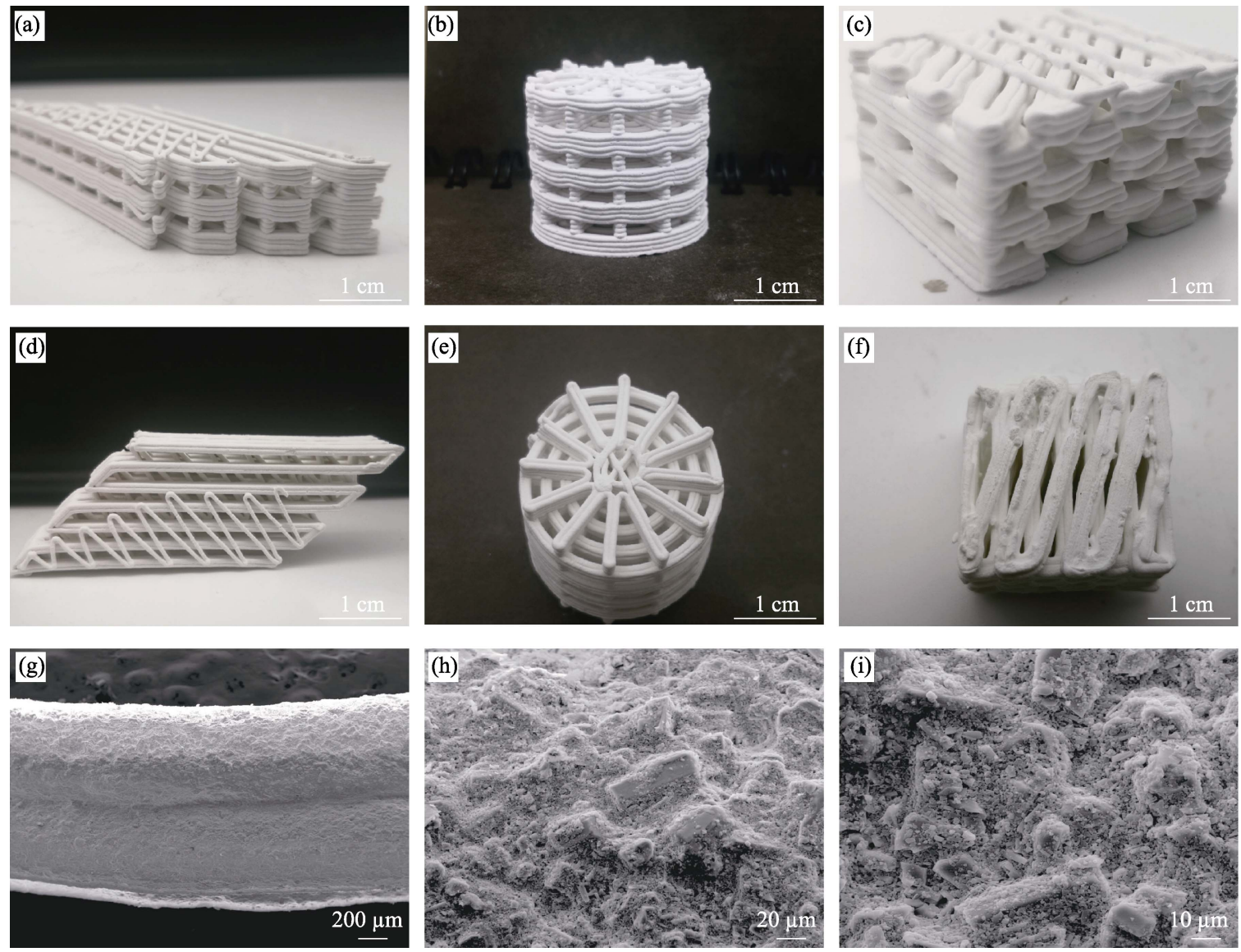

Fig. 3 Structures and microstructures of printed 3D gypsum

(a, d) Scaffold structure with three horizontal lines and three vertical lines appearing alternately and periodically in the $Z$-axis, the cross angle is $60^{\circ}$;

(b, e) Spider structure consisting of alternate layers of radial and circular rods; (c, f) Scaffold structure with three horizontal lines and three vertical lines appearing alternately and periodically in the $Z$-axis, the cross angle is $45^{\circ}$; (g-i) Microstructure of printed gypsum parts 
feature is obvious, which is compact due to the complete hydration undergoing DIW. The surface is relatively flat. The dihydrate crystals resulting from hydration are densely connected to each other, although few microsized holes are kept.

The compressive strength of gypsum samples fabricated by molds and DIW is shown in Fig. 4. The compressive strength of the gypsum samples by molds without and with CA (0.6\%) (in mass), are $\sim 44$ and $\sim 20 \mathrm{MPa}$, respectively. In general, the compressive strength of gypsum should be declined by adding CA, and the better the effect of a retarder is, the lower the mechanical properties of hydrated gypsum are ${ }^{[32]}$. So, CA isn't a suitable additive when the gypsum needs high strength. The compressive strength of the gypsum with HPMC and $\mathrm{CA}$ is $22 \mathrm{MPa}$, which is lower than that without additives. It is attributed to the addition of CA which affects the crystal growth (More explanation see Section 3). Compared to the compressive strength of gypsum containing CA with/without HPMC, it is interesting that HPMC plays a positive role in the enhancement of compressive strength. Moreover, the compressive strength of printed cube and cylinder is $\sim 16$ and $23 \mathrm{MPa}$, which is higher than that of the printed gypsum parts by Binder Jetting, around $10-13 \mathrm{MPa}^{[21]}$.

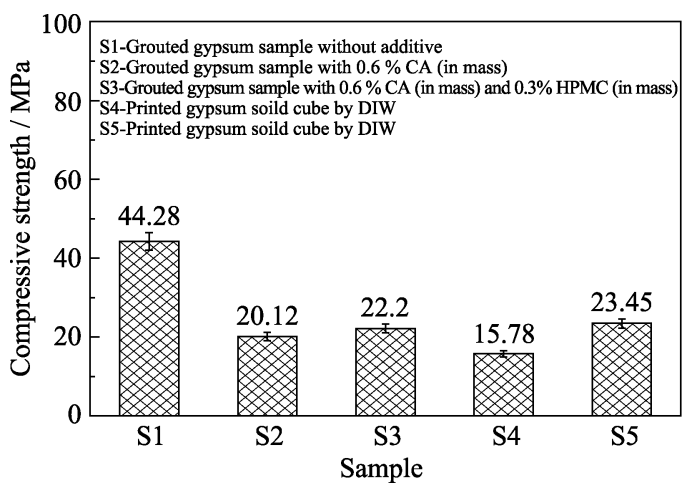

Fig. 4 Compressive strength of different gypsum samples

\section{Discussion}

The hydration reaction happens upon gypsum contact with water. Hemihydrate gypsum $(\mathrm{H})$ is dissolved into water and gradually precipitated out in the form of dihydrate gypsum (D) ${ }^{[33]}$. The transition of gypsum during hydration from $\mathrm{H}$ to $\mathrm{D}$ was monitored by XRD, as shown in Fig. 5. In the gypsum paste with CA, D is detected after a reaction about of $12 \mathrm{~min}$. The initial setting time, however, is $199 \mathrm{~min}$ (Fig. 1(a)). It implies that the dissolution of $\mathrm{H}$ and the formation of $\mathrm{D}$ regenerated gypsum crystal network happen simultaneously. With a precipitation of $\mathrm{D}$, the amount of free water is reduced, resulting in a decrease in fluidity. The initial setting time is set as the paste loses its fluidity completely. When all $\mathrm{H}$ has been dissolved and a crystal network of $\mathrm{D}$ has been formed preliminarily, the interlocked dihydrate crystal with a certain structural strength is formed. And thus, the paste has an initial strength at this time, called final setting time ${ }^{[34-35]}$. CA selectively absorbed on $\mathrm{H}$ or hinders precipitating $\mathrm{D}$ from water. Thus, the initial time of paste is prolonged by adding CA. Besides, the D crystal growth is inhibited by the selective absorption of $\mathrm{CA}$, which affects forming $\mathrm{D}$ crystal network $^{[34-35]}$.

The microstructure transition of gypsum with $\mathrm{CA} / \mathrm{HPMC}$ during hydration is shown in Fig. 6. In the gypsum paste with $\mathrm{CA}$, the prismatic gypsum crystals become shorter, smaller and more plate-like. Regarding HPMC, hydrogen bonds are formed between its functional group and water molecules, causing water molecules to be fixed or warped, forming more and more small groups of water and HPMC. These groups increase contact points between the precipitated D and fill crystal network gaps. The result is that the flocculation of $\mathrm{D}$ in the paste is accelerated, which is beneficial to obtaining a more compact crystal network ${ }^{[36]}$. As shown in Fig. 5, the XRD peaks of the pastes with HPMC and CA are
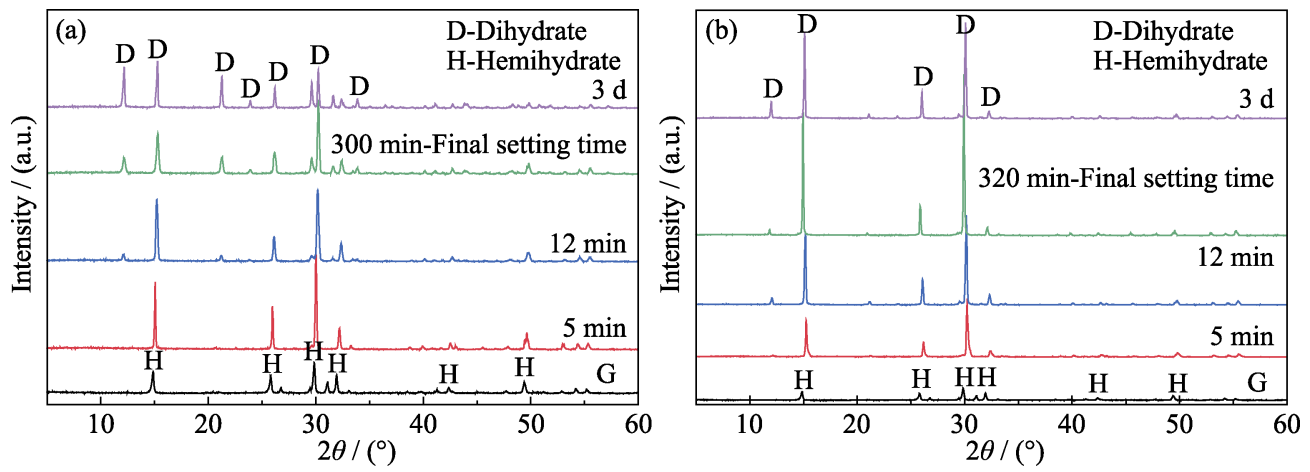

Fig. 5 XRD patterns at different hydration time for gypsum pastes with different agents

(a) $0.6 \%$ (in mass) citric acid gypsum at different hydration time; (b) $0.6 \%$ (in mass) citric acid and $0.3 \%$ (in mass) HPMC at different hydration time 
sharper than that with only $\mathrm{CA}$, indicating that the crystal degree of $\mathrm{D}$ is high in the former. That is, HPMC plays a positive role in the precipitation of $\mathrm{D}^{[36-37]}$. As illustrated in Fig. 6(e-h), accompanied by hydration reaction, the interconnected contact sites of D increase and the small $\mathrm{H}$ and $\mathrm{D}$ are embedded, which encourages the flocculation structure of D.

Selective absorption of CA on gypsum crystal affects the rheological property of gypsum paste. With the progress of hydration reaction, gypsum paste gradually transforms from flow to solid. The directional crystal growth caused by CA leads to smaller crystal size and slower hydration reaction, resulting in almost no change in the fluidity of the paste with time (Fig. 1(b)). On the other side, the intrinsic acidity of $\mathrm{CA}$ also has an
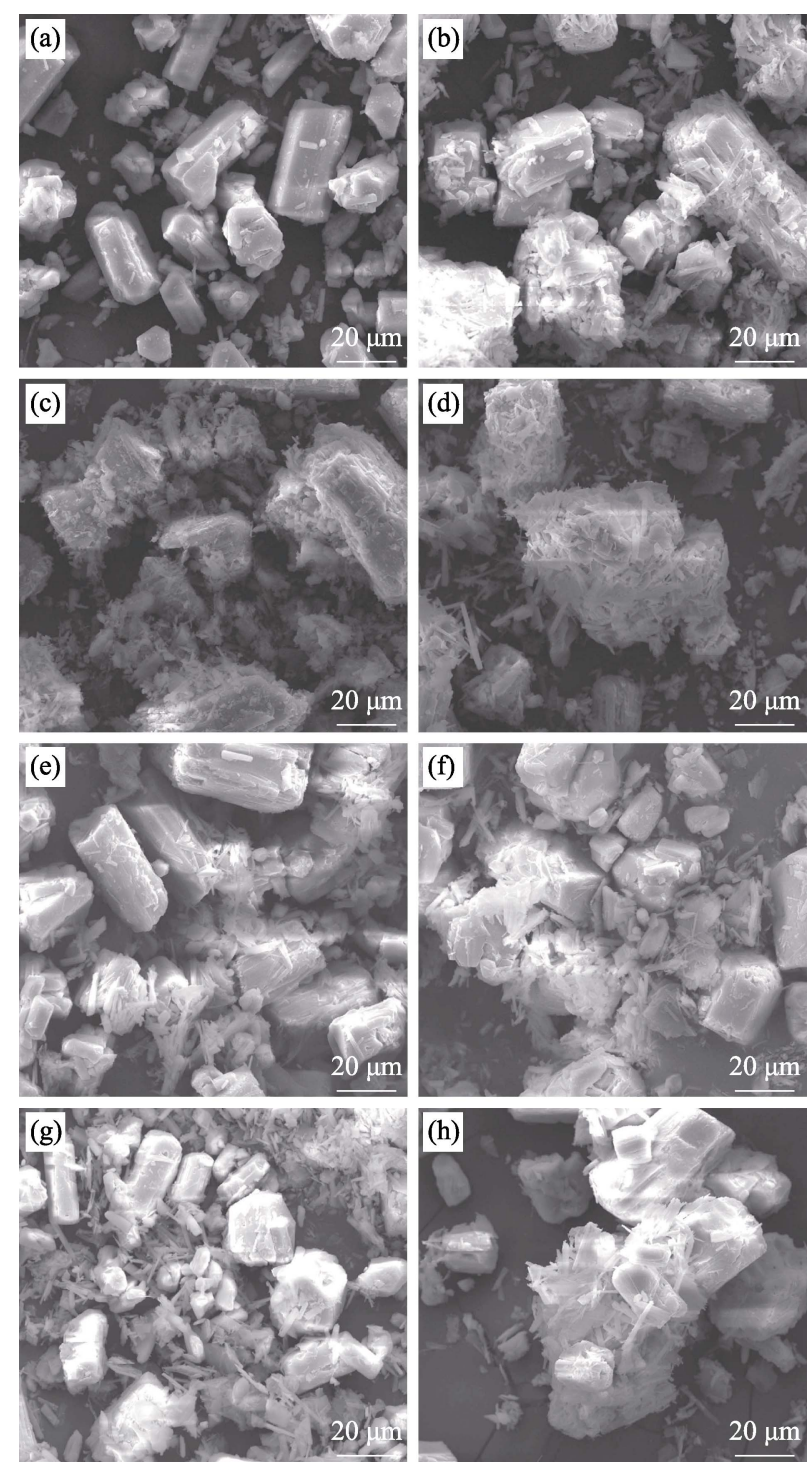

Fig. 6 SEM images of gypsum at different hydration time (a-d) Gypsum with $0.6 \%$ (in mass) CA at different hydration time ((a) 5 min, (b) 12 min, (c) $20 \mathrm{~min}$, (d) $300 \mathrm{~min}$ (final setting time)); (e-f) Gypsum with $0.6 \%$ (in mass) CA and $0.3 \%$ (in mass) HPMC at different hydration time ((e) $5 \mathrm{~min}$, (f) $12 \mathrm{~min}$, (g) $20 \mathrm{~min}$, (h) $320 \mathrm{~min}$ (final setting time)) influence on the $\mathrm{pH}$ of the gypsum paste. With the addition of $\mathrm{CA}$, the gypsum pastes experience a process from alkaline to acidic. When the content of $\mathrm{CA}$ is $0.6 \%$ (in mass), the $\mathrm{pH}$ of paste is 7-9, the complex formed by acid ions and $\mathrm{Ca}^{2+}$ has the highest stability ${ }^{[38]}$. Thus, the yield stress of paste is the highest as the content of CA is $0.6 \%$ (in mass) (Fig. 1(c,d)). After adding 0.6\% (in mass) HPMC into the paste CA, more water is captured by this polymer, which accelerates the flocculation of $\mathrm{D}$ and enhances the viscosity of gypsum. Therefore, there is a decrease of fluidity, an increment of shear elastic modulus and yield stress, with the content of HPMC increasing (Fig. 2).

Moreover, the mechanical properties of gypsum are also affected by CA and HPMC. During the hydration of a gypsum paste without additives, dihydrate crystals hide at the grain boundaries and trigger off growing along with the grain boundary space, forming thin flakes or fine needles of dihydrate gypsum dispersions at the crossed and connected place, resulting in a porous mesh structure. After the formation of this crystalline structure network, new hydration products continuously fill the gaps of this network. The crystal contact points keep increasing, and the Van der Waals force and chemical bonding forces are generated at the contact points of crystal intersection, which is sum up to the strength of gypsum $^{[33]}$. The selective adsorption of CA on dihydrate gypsum leads to directional crystal growth ${ }^{[39-40]}$, which decreases the contact point (Fig. 6(a-d)). Thus, the presence of $\mathrm{CA}$ hinders the hydration, prolonging the induction period of reaction and slowing down the hydration rate. Meanwhile, the nucleation rate of dehydrated is also reduced by CA. So, the compressive strength of the solidified paste is declined (Fig. 4). From this perspective, CA is not a good retarder for strength which is detrimental to mechanical strength.

\section{Conclusions}

To print three-dimensional gypsum structures by Direct Ink Writing, a printable gypsum paste is developed in this work. A retarder is introduced into the paste to retard the hydration reaction, and citric acid is chosen as a suitable one. In the hydration, CA selectively adsorbed on gypsum crystal affects its crystal growth resulting in a directional growth. Hydroxypropyl methylcellulose is used as a thickener to improve the shear elastic modulus of the paste. The optimal formula of the printable gypsum paste is $56 \%$ (in mass) of gypsum powder, $35 \%$ (in mass) of water, $0.6 \%$ (in mass) of CA, and $0.3 \%$ (in mass) of HPMC. Three-dimensional gypsum structures such as spider web and scaffolds were 
successfully printed via direct ink writing. The compressive strength of the printed gypsum parts is around $20 \mathrm{MPa}$. Although it is lower than that of a gypsum paste without a retarder and a thickener because of the directional crystal growth, it is much higher than that printed via Binder Jetting.

\section{References:}

[1] ZHANG J X, ZHANG Y, LIU J K, et al. Research on the properties of high-strength gypsum based tile adhesive in interior decoration. E3S Web of Conferences, 2020, 165(5): 05015.

[2] PHONGTHORN J, PANUWAT J. Utilization of several industrial wastes as raw material for calcium sulfoaluminate cement. Materials, 2019, 12(20): 3319-3331.

[3] PHETRATTANARANGSI T, PUNCREOBUTR C, KHAMKONGKAEO A, et al. The behavior of gypsum-bonded investment in the gold jewelry casting process. Thermochimica Acta, 2017, 657: 144-150.

[4] WEISE J, HILBERS J, HANDELS F, et al. New core technology for light metal casting. Advanced Engineering Materials, 2019, 21(4): 1800608.

[5] MA CHANGLIANG, ZHANG YUE, ZHANG HUANYUE, et al. Manufacturing of herringbone gear model by 3D printing assisted investment casting. IOP Conference Series Earth and Environmental Science, 2019, 332(4): 042045.

[6] MA Y, TANG B, YAO Q M, et al. Common defects and their solutions in plaster investment precision casting. Special Casting, 2020, 41(7): 664-666.

[7] SHEN Y, ZHENG G, FENG C M. Research progress in investment casting precision casting technology. Precision Forming Engineering, 2019(01): 54-62.

[8] HEAD D, VANORIO T. Effects of changes in rock microstructures on permeability: 3-D printing investigation. Geophysical Research Letters, 2016, 43(14): 7494-7502.

[9] LIGON S C, LISKA R, STAMPFL J, et al. Polymers for 3D printing and customized additive manufacturing. Chemical Reviews, 2017, 117(15): 10212-10290.

[10] AMBROSI A, PUMERA M. 3D-printing technologies for electrochemical applications. Chemical Society Reviews, 2016, 45(10): 2740-2755.

[11] HISHAM H H, ARIFIN S S, AYA A, et al. 3D printable conductive materials for the fabrication of electrochemical sensors: a mini review. Electrochemistry Communications, 2018, 96: 27-31.

[12] CIMA M, LEXINGTON, SACHS E M, et al. Three-dimensional Printing Techniques. U.S., Patent, 5387380, 1995.2.7.

[13] CASTILHO M, RODRIGUES J, PIRES I, et al. Fabrication of individual alginate-TCP scaffolds for bone tissue engineering by means of powder printing. Biofabrication, 2015, 7(1): 15004-15023.

[14] JARIWALA S H, LEWIS G S, BUSHMAN Z J, et al. 3D printing of personalized artificial bone scaffolds. $3 D$ Printing and Additive Manufacturing, 2015, 2(2): 56-64.

[15] SNYDER T J, ANDREWS M, WEISLOGEL M, et al. 3D systems' technology overview and new applications in manufacturing, engineering, science, and education. $3 D$ Printing and Additive Manufacturing, 2014, 1(3): 169-176.

[16] LIU H B, MENG F J, HUA S Z. 4D mapping of the fracture evolution in a printed gypsum-like core by using X-ray CT scanning. Advances in Civil Engineering, 2021, 2021: 1-12.

[17] SONG R, WANG Y, ISHUTOV S, et al. A comprehensive experimental study on mechanical behavior, microstructure and transport properties of 3D-printed rock analogs. Rock Mechanics and Rock Engineering, 2020, 53(12): 5745-5765.

[18] JAVAN R, ELLENBOGEN A L, GREEK N, et al. A prototype assembled 3D-printed phantom of the glenohumeral joint for fluoroscopic-guided shoulder arthrography. Skeletal Radiology, 2019, 48(5): 791-802.

[19] BUDA M, BRATOS M, SORENSEN J A. Accuracy of 3-dimensional computer-aided manufactured single-tooth implant definitive casts. Journal of Prosthetic Dentistry, 2018, 120(6): 913-918.

[20] RODRÍGUEZ-GONZÁLEZ P, FERNÁNDEZ-ABIA A I, CASTROSASTRE M A, et al. Heat treatments for improved quality binder jetted molds for casting aluminum alloys. Additive Manufacturing, 2020, 36: 101524.

[21] WU Z J, ZHANG B, WENG L, et al. A new way to replicate the highly stressed soft rock: 3D printing exploration. Rock Mechanics and Rock Engineering, 2020, 53(1): 467-476.

[22] ASADI-EYDIVAND M, SOLATI-HASHJIN M, SHAFIEI S S, et al. Structure, properties, and in vitro behavior of heat-treated calcium sulfate scaffolds fabricated by $3 \mathrm{D}$ printing. PLOS ONE, 2016, 11(3): e151216.

[23] SELVARAJ S B, SINGAMNENI S. Pre-moisturized $\beta$-hemihydrate for $3 \mathrm{~d}$ printed molds. Materials and Manufacturing Processes, 2015, 31(8): 1102-1112.

[24] SHAHARIAR H, KIM I, BHAKTA R, et al. Direct-write printing process of conductive paste on fiber bulks for wearable textile heaters. Smart Materials and Structures, 2020, 29(8): 085018.

[25] FIOCCO L, ELSAYED H, BADOCCO D, et al. Direct ink writing of silica-bonded calcite scaffolds from preceramic polymers and fillers. Biofabrication, 2017, 9(2): 025012.

[26] LIU C B, GAO J M, TANG Y B, et al. Preparation and characterization of gypsum-based materials used for 3D robocasting. Journal of Materials Science, 2018, 53(24): 16415-16422.

[27] ZHANG Y Y, YANG J S, CAO X Y. Effects of several retarders on setting time and strength of building gypsum. Construction and Building Materials, 2020, 240: 117927.

[28] HILL J, PLANK J. Retardation of setting of plaster of paris by organic acids: understanding the mechanism through molecular modeling. Journal of Computational Chemistry, 2004, 25(12): 1438-1448.

[29] GENSOWSKI K, TEPNER S, SCHWEIGERT S, et al Conductive highly filled suspensions for an electrochemical dispensing approach to pattern full-area thin metal layers by physical vapour deposition. Scientific Reports, 2020, 10(1): 27-31.

[30] HOWARD A BARNES. The yield stress-a review or ' $\pi \alpha v \tau \alpha$ $\rho \varepsilon 1$ '- everything flows? Journal of Non-Newtonian Fluid Mechanics, 1999, 81(1): 133-178.

[31] LIU C B, GAO J M, CHEN X M, et al. Effect of polysaccharides on setting and rheological behavior of gypsum-based materials. Construction and Building Materials, 2021, 267: 120922.

[32] CAMARINI G, PINTO M C C, MOURA A G D, et al. Effect of citric acid on properties of recycled gypsum plaster to building components. Construction and Building Materials, 2016, 124: 383-390.

[33] LIU C B, GAO J M, TANG Y B, et al. Early hydration and microstructure of gypsum plaster revealed by environment scanning electron microscope. Materials Letters, 2019, 234: 49-52.

[34] SINGH M, GARG M. Retarding action of various chemicals on setting and hardening characteristics of gypsum plaster at different pH. Cement and Concrete Research, 1997, 27(6): 947-950.

[35] QU J D, LI B Z, PENG J H. Influence of retarders on the microstructure of hardened building gypsum paste and the mech- 
anism of its strength loss. Advanced Materials Research, 2011, 250(253): 313-320.

[36] BÜLICHEN D, PLANK J. Water retention capacity and working mechanism of methyl hydroxypropyl cellulose (MHPC) in gypsum plaster-which impact has sulfate? Cement and Concrete Research, 2013, 46: 66-72.

[37] THOMPSON B R, HOROZOV T S, STOYANOV S D, et al. Hierarchically porous composites fabricated by hydrogel templating and viscous trapping techniques. Materials \& Design, 2018, 137: 384-393.
[38] MENG X L, WANG Q Q, WANG Y L. Effect of retarder on properties of FGD gypsum. Shandong Chemical Industry, 2019, 49(4): 17-18.

[39] MAGALLANES-RIVERA R X, ESCALANTE-GARCÍA J I, GOROKHOVSKY A. Hydration reactions and microstructural characteristics of hemihydrate with citric and malic acid. Construction and Building Materials, 2009, 23(3): 1298-1305.

[40] LANZÓN M, GARCÍA-RUIZ P A. Effect of citric acid on setting inhibition and mechanical properties of gypsum building plasters. Construction and Building Materials, 2012, 28(1): 506-511.

\title{
石膏的直写成型：可打印石膏浆料的研制
}

\author{
周红莉 ${ }^{1}$, 蔡志勇 ${ }^{1}$, 王小锋 ${ }^{1}$, 曾 婧 $^{2}$, 冯 艳 $^{1}$, 彭超群 ${ }^{1}$, 王日初 ${ }^{1}$ \\ (中南大学 1. 材料科学与工程学院, 长沙 410083; 2. 冶金与环境学院, 长沙 410083)
}

摘 要: 石膏是雕像、建筑和铸造模具(合金和陶瓷)的常用材料。采用直写成型(Direct Ink Writing, DIW)打印石膏可 避免其他 3D 打印技术(如 Binder Jetting, PBBJ 等)中存在水化反应不充分等问题, 获得高强度 3D 打印石膏。为了 延缓水化反应获得充足的打印操作时间, 本研究通过添加缓凝剂和增稠剂, 研制了一种适用于直写成型的石膏浆 料, 并打印了多种石膏三维结构(如蜘蛛网和木材堆积结构等)。结果表明, 质量分数为 $0.6 \%$ 柠檬酸 (Citric Acid, CA) 的缓凝效果最好, 极大地减少了石膏流动性的经时损失。质量分数为 $0.3 \%$ 羟丙基甲基纤维素 (Hydroxypropyl Methylcellulose, HPMC)的增稠效果最好, 使石膏浆料具有良好的打印性能。CA 的选择性吸附使得石膏晶体定向生 长, 延长水化反应时间, 但一定程度降低石膏强度。HPMC 加速石膏浆料中絮凝结构形成, 导致其粘度和剪切弹性 模量升高。直写成型 3D 石膏件的抗压强度约为 $20 \mathrm{MPa}$ ，远高于 PBBJ 等方法制备的石膏件的抗压强度。

关 键 词: 直写成型; 石膏; 缓凝剂; 增稠剂; 流变性能; 铸造

中图分类号: TQ174 文献标志码: A 